\title{
High chromogranin A cell density in the colon of patients with lymphocytic colitis
}

\author{
M. EL-SALHY ${ }^{1,2}$, B. LOMHOLT-BECK ${ }^{3}$ and T.D. GUNDERSEN ${ }^{4}$ \\ ${ }^{1}$ Section for Gastroenterology, Department of Medicine, Stord Helse-Fonna Hospital, Stord; \\ ${ }^{2}$ Section for Gastroenterology, Institute of Medicine, University of Bergen, Bergen; ${ }^{3}$ Department of Pathology, \\ Haugesund Helse-Fonna Hospital; ${ }^{4}$ Department of Research, Helse-Fonna, Haugesund, Norway
}

Received March 28, 2011; Accepted May 11, 2011

DOI: $10.3892 / \mathrm{mmr} .2011 .492$

\begin{abstract}
Microscopic colitis (MC) is a chronic condition that is characterized by watery diarrhoea with normal appearance of the colonic mucosa. MC is subdivided into two distinctive entities: lymphocytic colitis (LC) and collagenous colitis (CC). The etiology and pathophysiology of LC remain to be determined. The present study included 9 female patients with LC, with an average age of 34 years. Subjects $(n=25)$ who underwent colonoscopy were used as controls. The subjects underwent colonoscopy due to gastrointestinal bleeding, where the source of bleeding was identified as haemorrhoids, or due to health concerns. The control subjects included 18 females and 7 males, with an average age of 49 years. Colonoscopy was performed in both patient and control groups, and biopsies were obtained from different segments of the colon. The biopsies were immunostained with the avidin-biotin complex method for human leucocytes CD45, collagen type III and chromogranin A (CgA). CgA was quantified by computer image analysis. The density of $\mathrm{CgA}$-immunoreactive cells in patients with LC was significantly higher than that in controls. The high density of colonic $\mathrm{CgA}$, a common marker for endocrine cells, indicates the possibility that colonic hormones are involved in the pathophysiology of LC. Serotonin-containing cells are the major endocrine cell type in the colon and constitute approximately $88 \%$ of the total endocrine cell population. It is likely that the increase in colonic $\mathrm{CgA}$ in LC patients accounts for an increase in serotonin cells.
\end{abstract}

\section{Introduction}

Microscopic colitis (MC) is a chronic condition, which is characterized by watery diarrhoea with normal appearance of the colonic mucosa. However, histopathological examinations

Correspondence to: Professor Magdy El-Salhy, Section for Gastroenterology, Department of Medicine, Stord Helse-Fonna Hospital, Box 4000, 5409 Stord, Norway

E-mail: magdy.el-salhy@helse-fonna.no

Key words: chromogranin A, computer image analysis, diarrhoea, lymphocytic colitis, microscopic colitis of the colon revealed abnormal histology. This abnormality is of two distinctive types: lymphocytic colitis (LC) and collagenous colitis (CC). LC and CC exhibit colonic intraepithelial lymphocytosis, increase inflammatory cells within lamina propria and preserve crypt architecture. The incidence of LC has been reported to be $3.1 / 100,000$ per year and the prevalence to be $14.4 / 100,000(1,2)$.

The etiology and pathophysiology of LC have yet to be determined. The symptoms of LC suggest an abnormally rapid intestinal motility and a decrease in absorption of water. The neuroendocrine system of the gut plays a significant role in regulating gut motility and absorption of water and salts (3-6). It is reasonable, therefore, to assume that the colonic endocrine cells may be affected and may be involved in the pathophysiology of this disorder.

Chromogranin A $(\mathrm{CgA})$ is a $68-\mathrm{kDa}$ protein comprising 439 amino-acid residues, which was isolated for the first time from secretory granules of the bovine adrenal medulla $(7,9) . \mathrm{CgA}$ is co-stored and co-released with monoamines and peptide hormones of the adrenal medulla, pituitary gland, parathyroid, thyroid C-cells, pancreatic islets, endocrine cells of the gastrointestinal tract and sympathetic nerves $(7,8)$. The serum and tissue content of $\mathrm{CgA}$ serves as a marker for gut endocrine cells and tumours (7-9).

The present study aimed to establish a possible abnormality in colonic endocrine cells in LC patients, using $\mathrm{CgA}$ as a common marker for endocrine cells. Furthermore, the possibility that such abnormality plays a role in the pathophysiology of LC was explored.

\section{Materials and methods}

Patients and controls. Of those patients who were referred to our clinic due to watery diarrhoea, abdominal cramping and nausea, 9 were included in this study. These 9 female patients had an average age of 34 years (range 22-58). The patients underwent complete physical examination and were examined using blood tests: full blood count, electrolytes, calcium, inflammatory markers, liver tests and thyroid function tests.

Subjects $(n=25)$ who had undergone colonoscopy, were used as controls. Of these, 12 subjects underwent colonoscopy due to gastrointestinal bleeding, where the source of bleeding was identified as haemorrhoids, and 13 subjects underwent 


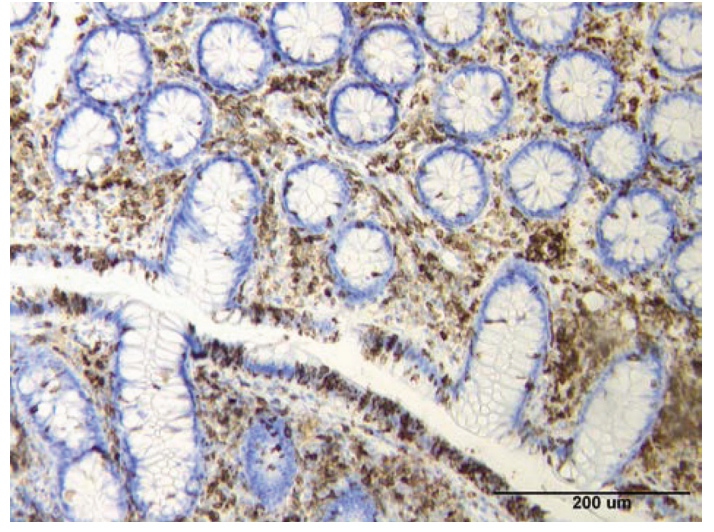

Figure 1. Photomicrograph of the colon of a patient with lymphocytic colitis as immunostained with CD45.

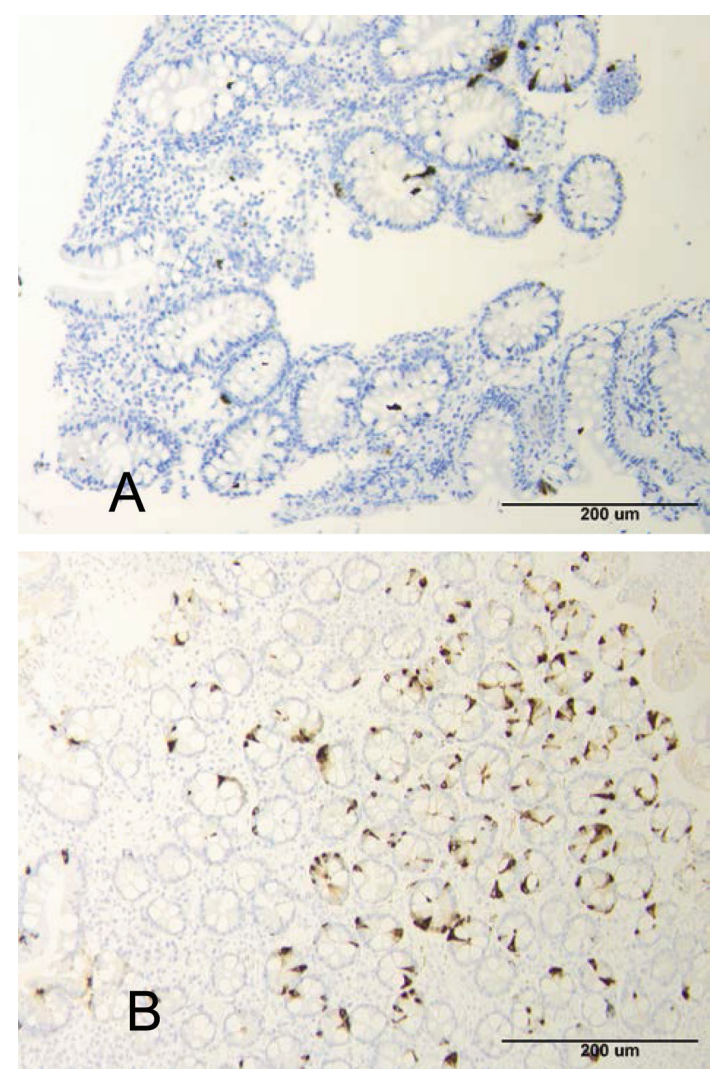

Figure 2. CgA-immunoreactive cells in the colon of (A) a control and (B) a patient with lymphocytic colitis.

colonoscopy due to health concerns caused by a relative(s) being diagnosed with colon carcinoma. The subjects included 18 females and 7 males, with an average age of 49 years (range 24-66).

Colonoscopy. Colonoscopy was carried out in patients and controls, and biopsies were obtained from the cecum, ascending colon, right and left halves of the transverse colon, descending colon and sigmoid colon. The biopsies were pooled together.

Histopathology and immunohistochemistry. Biopsies were fixed in $4 \%$ buffered paraformaldehyde overnight, embedded

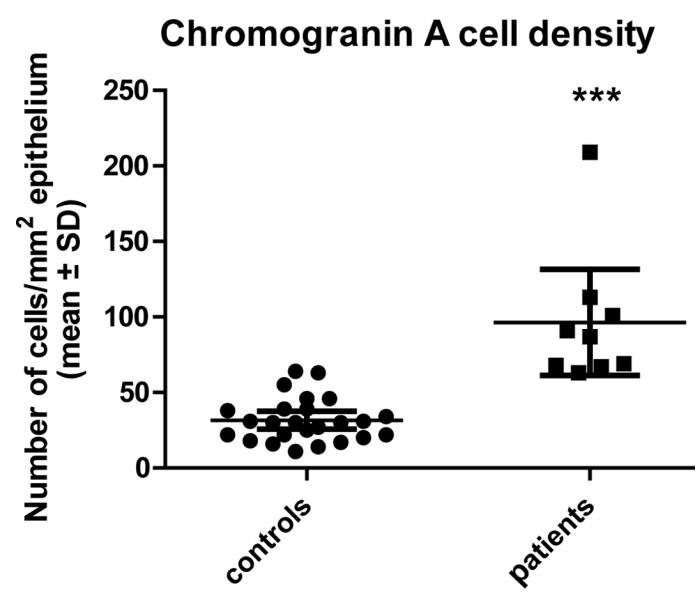

Figure 3. CgA-immunoreactive cell density in patients and the controls with lymphocytic colitis. ${ }^{* * *} \mathrm{P}<0.0001$.

in paraffin and cut into $5-\mu \mathrm{m}$ sections. The sections were stained with $\mathrm{H} \& \mathrm{E}$ and immunostained with the avidin-biotin complex (ABC) method using a Vectastain ABC-kit (Vector Laboratories, Burlingame, CA, USA), as previously described (10). The primary antibodies used were: monoclonal mouse anti-human leucocytes CD45 (DakoCytomation, Glostrup, Denmark, code no. IS751) monoclonal antibodies to collagen type III (Acris, code no. P02461) and monoclonal mouse antiN-terminal of purified chromogranin A (DakoCytomation, code no. M869). The second layer biotinylated mouse antiIgG was obtained from DakoCytomation. The stained and immunostained sections were examined for the possible occurrence of MC.

The diagnosis of LC required an increase in intraepithelial lymphocytes (>15 lymphocytes/100 epithelial cells) and surface epithelial damage with increased lamina propria plasma cells and absent or minimal crypt architectural distribution. For the diagnosis of $\mathrm{CC}$, an increase/irregularity in sub-epithelial collagen $(>10 \mu \mathrm{m})$ that trapped superficial capillaries was required in addition to the other inflammatory changes observed in LC (11).

Computerized image analysis. Computerized image analysis was performed using Olympus software: Cell $\wedge^{\wedge} \mathrm{D}$. When using x20 objectives, the frame (field) on the monitor shows an area of $0.14 \mathrm{~mm}^{2}$ of the tissue. The number of $\mathrm{CgA}$ immunoreactive cells and the area of the epithelial cells were measured in each field. Measurements were taken in 10 randomly selected fields for each individual. The data from the fields were tabulated, and the number of cells $/ \mathrm{mm}^{2}$ of the epithelium was computed and statistically analysed automatically.

Statistical analysis. As the results of controls and patients passed the normality test, the t-test was performed. $\mathrm{P}<0.05$ was considered to be statistically significant.

\section{Results}

Colonoscopy, histopathology and immunohistochemistry. The colon of patients and control subjects was macroscopically normal. 
Histopathological examination of the colon biopsies from the controls revealed normal histology. All of the patients fulfilled the criteria for LC (Fig. 1). In the colon of both patients and control subjects, immunostaining for collagen III did not reveal any abnormality. $\mathrm{CgA}$ immunoreactive cells were found in the colon of both patients and the controls. $\mathrm{CgA}$ cells were mostly located in the upper part of the crypts of Lieberkühn (Fig. 2). These cells were basket- or flask-shaped.

Computerized image analysis. The $\mathrm{CgA}$ density in the controls was found to be $31.3 \pm 14.5$ (mean \pm SD). The corresponding figure for LC patients was $96.4 \pm 45.6$. The density of CgA-immunoreactive cells in patients with LC was significantly higher than that of the controls $(\mathrm{P}<0.0001)$ (Fig. 3).

\section{Discussion}

MC occurs at all ages in both men and women, but is more common in middle-aged women $(11,12)$. It is a common cause of watery diarrhoea, abdominal cramping and nausea $(13,14)$. Epidemiological studies in Spain and Sweden estimate the prevalence of MC at approximately $10 \%$ of all patients with chronic diarrhoea $(15,16)$. The cause and pathophysiology of $\mathrm{MC}$ remains unclear. It has been speculated that MC may be the result of an abnormal immune response to bowel contents, such as bacterial toxins and medicinal products or food (12). It was also attributed to abnormal collagen metabolism (12).

The present finding of high density of colonic $\mathrm{CgA}$, a common marker for endocrine cells, suggests that colonic hormones are involved in the pathophysiology of LC. The specific cell type to which this increase may be attributed remains to be determined. However, serotonin-containing cells are the major endocrine cell type in the colon and constitute approximately $88 \%$ of the total endocrine cell population as revealed by $\mathrm{CgA}(17,18)$. It is conceivable that the increase in colonic $\mathrm{CgA}$ in $\mathrm{LC}$ patients accounts for an increase in serotonin cells. Serotonin is thought to activate the submucosal sensory branch of the enteric nervous system and control, and accelerates gastrointestinal motility via interneurons and motor neurons $(19,20)$. If this hypothesis were proven to be the case, diarrhoea, abdominal cramping and nausea symptoms could be explained on this basis. This assumption is supported by the observation of an association between serotonin reuptake inhibitors and MC (21).

The age and gender of the patients and healthy controls used in this investigation did not match completely. In previous studies, however, age and gender have been found to have no effect on the density of intestinal endocrine cells in adults $(22,23)$.

In conclusion, the present study indicates that the colonic hormones, most probably serotonin, are involved in the pathophysiology of LC.

\section{Acknowledgements}

The authors wish to thank Ann-Kristin Koppang for her enthusiasm and for keeping the patient record in order. Thanks are due to Åsa Helene Lundal at the Department of Pathology, Haugesund Hospital, for co-ordination of the collaboration between Stord and Haugesund hospitals. We would like to express our gratitude to Professor Hans Olav Fadnes, Head of the Department of Medicine, Stord Helse-Fonna Hospital, for his support and for reading the manuscript. This study was supported by a grant from Helse-Fonna.

\section{References}

1. Fernandez-Banares F, Salas A, Forne M, Esteve M, Espinos J and Viver JM: Incidence of collagenous and lymphocytic colitis: a 5-year population-based study. Am J Gastroenterol 94: 418-423, 1999.

2. Bohr J, Tysk C, Eriksson S and Jarnerot G: Collagenous colitis in Orebro, Sweden, an epidemiological study 1984-1993. Gut 37: 394-397, 1995.

3. Goya PK and Hirano I: Mechanisms of disease: the enteric nervous system. N Engl J Med 334: 1106-1615, 1996.

4. McConalouge $\mathrm{K}$ and Furness JB: Gastrointestinal neurotransmitters. Baillieres Clin Endocrinol Metab 8: 51-76, 1994.

5. Debas HT and Mulvihill SJ: Neuroendocrine design of the gut. Am J Surg 161: 243-249, 1991.

6. El-Salhy M: Gut neuroendocrine system in diabetes gastroenteropathy: possible role in pathophysiology and clinical implications. In: Focus on Diabetes Research. Ashley M (ed). Nova Science Publisher, New York, pp79-102, 2006.

7. Taupenot L, Harper KL and O'Connor DT: The chromograninsecretogranin family. N Engl J Med 348: 1134-1149, 2003.

8. Wicdenmann B and Huttner WB: Synaptophysin and chromogranin/secretogranins-widespread constituents of distinct types of neuroendocrine vesicales and new tools in tumor diagnosis. Virchows Arch B Cell Pathol 58: 95-121, 1989.

9. Deftos LJ: Chromogranin A: its role in endocrine function and as an endocrine and neuroendocrine tumor marker. Endocrine Rev 12: 181-188, 1991

10. El-Salhy M, Stenling R and Grimelius L: Peptidergic innervation and endocrine cells in the human liver. Scand J Gastroenterol 28: 809-815, 1993.

11. Pardi DS, Smyrk TC, Termaine WJ, et al: Microscopic colitis: a review. Am J Gastroenterol 97: 794-802, 2002.

12. Van der Wouden EJ, Karreenbeld A, Kleibeuker JH and Dijkstra G: Microscopic colitis: an unfamiliar but treatable disease. Neth J Med 67: 41-45, 2009.

13. Lazenby AJ, Yardley JH, Giardiello FM, Jessurun J and Baylyese TM: Lymphocytic (microscopic) colitis: a comparative histopathologic study with particular reference to collagenous colitis. Hum Pathol 20: 18-28, 1989.

14. Chande N, Dirman DK and Reynolds RP: Collagenous colitis and lymphocytic colitis: patient characteristics and clinical presentation. Scand J Gastroenterol 14: 943-947, 2000.

15. Femandez-Banares F, Salas A, Forne M, Esteve M, Espinos J and Viver JM: Incidence of collagenous and lymphocytic colitis: a 5 year population-based study. Am J Gastroentrol 94: 418-423, 1999.

16. Olesen M, Eriksson S, Bohr J, Jarnerot G and Tysk C: Microscopic colitis: a common diarrhoeal disease. An epidemiological study in Örebro, Sweden 1993-1998. Gut 53: 346-350, 2004.

17. El-Salhy M, Lomholt-Beck B and Hausken T: Chromogranin as a possible tool in the diagnosis of irritable bowel syndrome. Scan J Gastroenterol 45: 35-39, 2010.

18. El-Salhy M, Gundersen D, Østgaard H, Lomholt-Beck B, Hatlebakk JG and Hausken T: Low densities of serotonin and peptide YY cells in the colon of patients with irritable bowel syndrome. Dig Dis Sci (In press).

19. Gershon MD: Plasticity of serotonin control mechanisms in the gut. Curr Opin Pharmacol 3: 600-607, 2003.

20. Kelum J, Albuqeque FC, Stoner MC and Harris RP: Stroking human jejunal mucosa induces 5-HT release and Cl-secretion via afferent neurons and 5-HT4 receptor. Am J Physiol 277: G515-G520, 1999.

21. Femandez-BanaresF,Esteve M,Espinos J,et al:Drug consumption and the risk for microscopic colitis. Am J Gastroenterol 102: 324-330, 2007.

22. Sandström O and El-Salhy M: Aging and endocrine cells of human duodenum. Mech Ageing Dev 108: 39-48, 1999.

23. Sandström O and El-Salhy M: Human rectal endocrine cells and aging. Mech Ageing Dev 108: 219-226, 1999. 